\title{
Mitochondrial DNA analysis in the Turkish Leber's hereditary optic neuropathy population
}

C.F. DOGULU, T. KANSU,

V. SEYRANTEPE, M. OZGUC,

H. TOPALOGLU, D.R. JOHNS

\section{Abstract}

Purpose To define the prevalence of a panel of mitochondrial DNA (mtDNA) mutations associated with Leber's hereditary optic neuropathy (LHON) in the Turkish LHON population. LHON-associated mtDNA mutations have been found in LHON patients from around the world, but the Turkish LHON population has not been studied. Methods Thirty-two Turkish patients were defined clinically as having LHON on the basis of painless, subacute, bilateral optic neuropathy and the exclusion of other causes of subacute optic neuropathy. mtDNA was extracted from blood of the 32 probands and assayed for a panel of primary and secondary LHON-associated mtDNA mutations by polymerase chain reaction (PCR)-based methods. We studied three well-known LHON-associated primary mutations (at nucleotide positions 11778, 3460 and 14484) and one common secondary mutation (at nucleotide 15257) in all 32 probands. In addition to these mutations, 18 of the 32 probands were tested for the Complex IV, COX III gene, LHON associated 9804 and 9438 mutations and secondary LHON mutations at nucleotide positions 3394, 4160, 4216, 4917, 5244, 7444, 7706, 13708, 13730 and 15812. Results Among the 32 probands tested for four common LHON mutations, 3 carried the 14484 mutation, 1 carried the 11778 mutation, 1 carried the 3460 mutation and 1 carried the 15257 mutation. Among the 18 LHON patients who tested for additional mutations, 1 proband harboured the 9804 mutation and 4 carried the secondary mutations at nucleotide positions 4216, 4917 and 13708.

Conclusion The results of mtDNA analysis of the Turkish LHON patients appear to be different from those of previous reports.

Key words LHON, mtDNA, mtDNA mutations

Leber's hereditary optic neuropathy (LHON) is a maternally inherited disease of young adults, predominantly males, characterised by acute or subacute, simultaneous or sequential, bilateral central visual loss and, ultimately, optic atrophy. LHON is the first human disease associated with a mtDNA point mutation. ${ }^{1}$ Analysis of the mtDNA molecules of LHON patients of different ethnic groups has indicated that three point mutations at nucleotide positions (np) 11778 (ND4 gene), 3460 (ND1 gene) and 14484 (ND6 gene), all of which occur in subunits of Complex I of the mitochondrial respiratory chain, have a primary pathogenetic significance in LHON. All three of these mutations alter evolutionarily conserved amino acids, and are not found in control individuals. They seem to be sufficient in themselves to cause the disease. The relative frequency of the three primary LHON mtDNA mutations varies considerably between populations, although the 11778 is the most prevalent mutation. The ND4/11778 mutation accounts for $50-76 \%$ of all LHON families, the ND1/3460 mutation is detected in $7-30 \%$ of cases and $10-31 \%$ of LHON families have the ND6/14484 mutation. ${ }^{1-5}$

Recently, two missense mutations at np 9438 and 9804 , in the cytochrome $c$ oxidase subunit III gene (Complex IV), have been identified in 8 independent LHON probands who lack the three primary LHON mutations, and it has been proposed that these mutations are of primary pathogenetic importance in LHON. ${ }^{6}$ The Complex IV, COX III/9804 mutation has been found in 3 probands, and the COX III/9438 mutation in 5 probands; neither has been found in controls.

In addition to these primary mutations, several other mutations of uncertain significance - so-called secondary mutations at np 3394 (Complex I/ND1 gene), 4160 (Complex I/ND1 gene), 4216 (Complex I/ND1 gene), 4917 (Complex I/ND2 gene), 5244 (Complex I/ND2 gene), 7444 (Complex IV/COXI gene), 7706 (Complex IV/COXII gene), 13708 (Complex I/ND5 gene), 13730 (Complex I/ND5 gene) and 15812 (Complex III/apocyt b gene) - have been reported in LHON pedigrees. ${ }^{7-10}$ These mutations are also detected at low frequency in control individuals, and they change evolutionarily less conserved amino acids. It has been suggested that secondary LHON
C.F. Dogulu

T. Kansu

Institute of Neurological

Sciences and Psychiatry

Department of Neurology

Neuro-Ophthalmology Unit

Hacettepe University

Ankara, Turkey

V. Seyrantepe

M. Ozguc

Department of Medical

Biology

Hacettepe University

Faculty of Medicine

Ankara, Turkey

H. Topaloglu

Department of Neurology

Pediatric Neurology Division

Hacettepe University

Hospitals

Ankara, Turkey

\section{D.R. Johns}

Department of Neurology

Neuromuscular Disease

Division

Beth Israel Hospital

Harvard Medical School

Boston, MA, USA

Cigdem F. Dogulu, MD Hacettepe University

Hospitals

Department of Neurology Ankara 06100, Turkey

Tel: +90 3123051806

Fax: +90 3123093451

e-mail: cd05-k@tr-net.net.tr

A part of this work was presented at the 1997 AAN Meeting

Received: 27 March 2000 Accepted in revised form: 5 September 2000 
Table 1. Ophthalmological findings of the Turkish LHON patients

\begin{tabular}{|c|c|c|c|c|c|c|c|c|c|c|}
\hline \multirow[b]{2}{*}{ Patient no. } & \multirow[b]{2}{*}{ Sex } & \multirow{2}{*}{$\begin{array}{l}\text { Age of onset } \\
\text { (years) }\end{array}$} & \multirow[b]{2}{*}{ Onset interval } & \multirow[b]{2}{*}{ Family history } & \multicolumn{2}{|c|}{ Visual acuity } & \multicolumn{2}{|c|}{ Colour vision } & \multirow[b]{2}{*}{ Fundal abnormalities } & \multirow[b]{2}{*}{ Visual field defect } \\
\hline & & & & & $\mathrm{R}$ & $\mathrm{L}$ & $\mathrm{R}$ & $\mathrm{L}$ & & \\
\hline 1 & $\mathrm{M}$ & 17 & Simultaneous & - & LP & CF 1 & $0 / 12$ & $0 / 12$ & Bilateral optic atrophy & $\begin{array}{l}\text { Right total loss, left dense central } \\
\text { scotoma }\end{array}$ \\
\hline 2 & $\mathrm{~F}$ & 28 & Sequential (5 years) & - & nLP & nLP & $0 / 12$ & $0 / 12$ & Bilateral optic atrophy & Bilateral total loss \\
\hline 3 & $\mathrm{M}$ & 21 & Simultaneous & - & CF 1 & CF 1 & $0 / 12$ & $0 / 12$ & Bilateral optic atrophy & Bilateral dense central scotoma \\
\hline 4 & M & 52 & Simultaneous & + & $\mathrm{nLP}$ & $\mathrm{nLP}$ & $0 / 12$ & $0 / 12$ & $\begin{array}{l}\text { Bilateral hyperaemic optic discs, } \\
\text { peripapillary microangiopathy }\end{array}$ & Bilateral total loss \\
\hline 5 & $\mathrm{M}$ & 15 & Simultaneous & - & $20 / 200$ & $20 / 200$ & $4 / 12$ & $6 / 12$ & Bilateral optic atrophy & Bilateral central scotoma \\
\hline 6 & $\mathrm{M}$ & 18 & Sequential (3 days) & - & CF 1 & CF 1 & $0 / 12$ & $0 / 12$ & Bilateral optic atrophy & Bilateral dense scotoma \\
\hline 7 & $\mathrm{M}$ & 17 & Sequential (3 months) & - & $20 / 800$ & $20 / 400$ & $1 / 12$ & $1 / 12$ & Bilateral optic atrophy & Bilateral dense central scotoma \\
\hline 8 & $\mathrm{M}$ & 18 & Sequential ( 2 weeks) & - & $20 / 200$ & CF 1 & $8 / 12$ & $0 / 12$ & Bilateral optic atrophy & Bilateral central scotoma \\
\hline 9 & M & 11 & Simultaneous & - & $20 / 200$ & $20 / 200$ & $0 / 12$ & $0 / 12$ & Bilateral optic atrophy & Bilateral central scotoma \\
\hline 10 & $\mathrm{M}$ & 14 & Simultaneous & + & $20 / 200$ & $20 / 200$ & $0 / 12$ & $0 / 12$ & Bilateral optic atrophy & Bilateral central scotoma \\
\hline 11 & $\mathrm{M}$ & 44 & Simultaneous & - & CF 1 & CF 1 & $0 / 12$ & $0 / 12$ & Bilateral optic atrophy & Bilateral dense central scotoma \\
\hline 12 & $\mathrm{M}$ & 21 & Simultaneous & - & LP & LP & $0 / 12$ & $0 / 12$ & Bilateral optic atrophy & Bilateral dense scotoma \\
\hline 13 & $\mathrm{M}$ & 18 & Simultaneous & - & CF 1 & CF 1 & $0 / 12$ & $0 / 12$ & Bilateral optic atrophy & Bilateral dense scotoma \\
\hline 14 & M & 20 & Simultaneous & - & CF 1 & CF 1 & $0 / 12$ & $0 / 12$ & Bilateral optic atrophy & Bilateral dense central scotoma \\
\hline 15 & $\mathrm{M}$ & 13 & Simultaneous & - & CF 1 & CF 1 & $0 / 12$ & $0 / 12$ & Bilateral optic atrophy & Bilateral dense central scotoma \\
\hline 16 & $\mathrm{~F}$ & 15 & Simultaneous & - & CF 1 & CF 1 & $0 / 12$ & $0 / 12$ & $\begin{array}{l}\text { Bilateral hyperaemic optic discs, } \\
\text { peripapillary microangiopathy }\end{array}$ & Bilateral dense central scotoma \\
\hline 17 & $\mathrm{~F}$ & 45 & Sequential (1 month) & - & LP & $20 / 800$ & $0 / 12$ & $0 / 12$ & $\begin{array}{l}\text { Bilateral hyperaemic optic discs, } \\
\text { peripapillary microangiopathy }\end{array}$ & Right total loss, left central scotoma \\
\hline 18 & $\mathrm{~F}$ & 46 & Simultaneous & - & $\mathrm{nLP}$ & nLP & $0 / 12$ & $0 / 12$ & $\begin{array}{l}\text { Bilateral hyperaemic optic discs, } \\
\text { peripapillary microangiopathy }\end{array}$ & Bilateral total loss \\
\hline 19 & $\mathrm{~F}$ & 18 & Sequential (2 weeks) & - & $20 / 200$ & $20 / 400$ & $4 / 12$ & $1 / 12$ & Bilateral optic atrophy & Bilateral central scotoma \\
\hline 20 & $\mathrm{~F}$ & 42 & Simultaneous & - & $20 / 200$ & $20 / 200$ & $6 / 12$ & $6 / 12$ & Bilateral optic atrophy & Bilateral central scotoma \\
\hline 21 & M & 14 & Sequential (3 weeks) & - & $20 / 200$ & $20 / 800$ & $4 / 12$ & $0 / 12$ & $\begin{array}{l}\text { Bilateral hyperaemic optic discs, } \\
\text { peripapillary }\end{array}$ & Bilateral dense central scotoma \\
\hline 22 & M & 15 & Sequential (1 year) & - & $20 / 400$ & $20 / 400$ & $0 / 12$ & $0 / 12$ & Bilateral optic atrophy & Bilateral dense central scotoma \\
\hline 23 & $\mathrm{~F}$ & 51 & Sequential (3 months) & - & $20 / 200$ & $20 / 200$ & $4 / 12$ & $4 / 12$ & Bilateral optic atrophy & Bilateral central scotoma \\
\hline 24 & M & 38 & Sequential ( 2 years $)$ & - & $20 / 200$ & $20 / 200$ & $5 / 12$ & $4 / 12$ & Bilateral optic atrophy & Bilateral central scotoma \\
\hline 25 & M & 41 & Sequential (4 months) & - & LP & $\mathrm{nLP}$ & $0 / 12$ & $0 / 12$ & Bilateral optic atrophy & Bilateral total loss \\
\hline 26 & $\mathrm{~F}$ & 23 & Sequential (5 months) & + & CF 1 & $20 / 800$ & $0 / 12$ & $0 / 12$ & Bilateral optic atrophy & Bilateral dense central scotoma \\
\hline 27 & M & 18 & Sequential ( 3 months) & - & $20 / 200$ & $20 / 200$ & $1 / 12$ & $1 / 12$ & $\begin{array}{l}\text { Bilateral hyperaemic optic discs, } \\
\text { peripapillary microangiopathy }\end{array}$ & Bilateral central scotoma \\
\hline 28 & $\mathrm{~F}$ & 16 & Simultaneous & - & $20 / 200$ & $20 / 200$ & $5 / 12$ & $5 / 12$ & $\begin{array}{l}\text { Bilateral hyperaemic optic discs, } \\
\text { peripapillary microangiopathy }\end{array}$ & Bilateral central scotoma \\
\hline 29 & $\mathrm{~F}$ & 36 & Sequential (1 year) & - & $20 / 200$ & nLP & $0 / 12$ & $0 / 12$ & Bilateral optic atrophy & Right central scotoma, left total loss \\
\hline 30 & M & 15 & Simultaneous & - & $20 / 400$ & $20 / 200$ & $0 / 12$ & $0 / 12$ & Bilateral optic atrophy & Bilateral central scotoma \\
\hline 31 & M & 16 & Sequential (1 month) & - & $20 / 400$ & $20 / 400$ & $0 / 12$ & $0 / 12$ & Bilateral optic atrophy & Bilateral dense central scotoma \\
\hline 32 & M & 24 & Simultaneous & - & CF 1 & CF 1 & $0 / 12$ & $0 / 12$ & Bilateral optic atrophy & Bilateral dense central scotoma \\
\hline
\end{tabular}

LP, light perception; nLP, no light perception; CF 1, Counting fingers at $1 \mathrm{~m}$. 
mutations may act synergistically with each other and with the primary mutations or nuclear factors and increase the risk of disease expression. ${ }^{11}$ The role of Complex III-apocytochrome $b$ gene, 15257 mutation, in the pathogenesis of LHON remains is a matter of debate. It is postulated to be of primary pathogenetic importance in LHON on account of the replacement of an evolutionarily highly conserved amino acid by the mutation. ${ }^{12}$ On the other hand the 4917 mutation also changes a highly conserved amino acid but certainly has no primary pathogenetic importance, if any phenotypic importance at all. ${ }^{9,13,14}$ Furthermore, it is found in $0.3 \%$ of normal controls and in combination with each of the 3460, 11778 and 14484 mutations, and Oostra et al. ${ }^{15}$ have suggested that these are the points against the mtDNA mutation at np 15257 being of primary pathogenetic significance.

All these LHON-associated mtDNA mutations have been found in LHON patients around the world. The purpose of this study was to define the prevalence of the LHON-associated mutations in the Turkish LHON population.

\section{Patients and methods}

\section{Patients}

Thirty-two patients (22 males, 10 females) were defined clinically as having LHON on the basis of painless, subacute bilateral optic neuropathy and the exclusion of other causes of subacute optic neuropathy. The results of an extensive evaluation including complete blood count, coagulation studies, serum folic acid and vitamin $B_{12}$ levels, analysis of cerebrospinal fluid and brain MRI were normal in all patients. Blood tests for syphilis, HIV and other viral infections were negative. Except for optic neuropathy, neurological and systemic examinations were normal. The age of onset was 11-51 years for males and 15-51 years for females. The two eyes were affected sequentially ( 3 days to 5 years) in 15 patients and simultaneously in 17 patients. No family history of visual loss was obtained in 29 patients. In 2 patients, one had a maternal uncle and the other had a brother with a history of visual loss. In 1 proband, a maternal uncle, a maternal aunt and a brother were visually affected. Colour vision was affected severely (with Ishihara colour plates), visual acuity was documented 20/200 or worse (with a Rosenbaum near vision chart) and visual fields demonstrated central defects (with Goldmann perimetry) in all patients. Fundoscopic examination demonstrated characteristic findings of LHON (circumpapillary telangiectatic microangiopathy and swelling of the optic disc with the absence of leakage on fluorescein angiography) in 7 patients who presented in the early stage of visual loss, and optic atrophy in 25 patients.

Clinical details are summarised in Table 1.

\section{Methods}

Molecular genetic analysis for a panel of three wellknown (at np 11778, 3460 and 14484) and two recently reported (at np 9438 and 9804) primary and 11 secondary (at np 3394, 4160, 4216, 4917, 5244, 7444, 7706, 13708, 13730, 15257 and 15812) LHON-associated mtDNA point mutations was performed on blood samples of 18 of the 32 Turkish LHON probands. The remaining 14 probands were tested for only four common LHON mutations (three primary: at np 11778, 3460, 14484; one secondary: at $n p$ 15257) by polymerase chain reaction (PCR)-based methods. DNA was extracted by standard proteinase $\mathrm{K} / \mathrm{SDS}$ methods, and PCR amplification was performed with $4 \mu$ l template DNA, $35 \mu \mathrm{l} \mathrm{dH20,5} \mu \mathrm{l} 10 \times$ PCR buffer, $4 \mu \mathrm{l}$ dNTPs, $2 \mu \mathrm{l}$ forward primer, $2 \mu$ l reverse primer and $0.5 \mu \mathrm{l}$ Taq polymerase. Mutation detection was performed by means of restriction endonuclease digestion. Amplified DNA was digested with restriction enzymes and the fragments were analysed by polyacrylamide gel electrophoresis and ethidium bromide staining.

Table 2. Oligonucleotide primers for PCR amplifications and restriction endonucleases

\begin{tabular}{|c|c|c|c|}
\hline \multirow[b]{2}{*}{ mtDNA point mutations } & \multicolumn{2}{|c|}{ Oligonucleotide primers $^{a}$} & \multirow[b]{2}{*}{ Restriction endonucleases } \\
\hline & Forward & Reverse & \\
\hline \multicolumn{4}{|l|}{ Primary mutations } \\
\hline 11778 & 11429-11449 & 11929-11909 & SfaNI (New England BioLabs) \\
\hline 3460 & 3787-3801 & 3081-3064 & BsaHI (New England BioLabs) \\
\hline 14484 & $14519-14538$ & $14483-14463$ & Sau3AI (New England BioLabs) \\
\hline 15257 & $15731-15748$ & $15115-15101$ & AccI (New England BioLabs) \\
\hline 9804 & 9756-9775 & $9866-9848$ & MaeIII (Boehringer Mannheim) \\
\hline 9438 & $9151-9169$ & $9581-9561$ & StuI (New England BioLabs) \\
\hline \multicolumn{4}{|l|}{ Secondary mutations } \\
\hline 3394 & 3064-3081 & $3650-3636$ & HaeIII (New England BioLabs) \\
\hline 4160 & & $4351-4337$ & AluI (New England BioLabs) \\
\hline 4216 & $4060-4074$ & $4351-4337$ & NIaIII (New England BioLabs) \\
\hline 4917 & $4850-4864$ & $5120-5103$ & BfaI (New England BioLabs) \\
\hline 5244 & $4704-4721$ & $5480-5463$ & HpaII (New England BioLabs) \\
\hline 7444 & $6924-6938$ & $8079-8061$ & XbaI (New England BioLabs) \\
\hline 7706 & $7407-7425$ & 8079-8061 & AccL (New England BioLabs) \\
\hline 13708 & $13900-13917$ & $13586-13569$ & BstNI (New England BioLabs) \\
\hline 15812 & $15101-15115$ & $16074-16060$ & RsaI (New England BioLabs) \\
\hline
\end{tabular}

${ }^{a}$ Primer pairs are numbered according to the canonical Cambridge human mtDNA sequence with the $5^{\prime} \rightarrow 3^{\prime}$ coordinates. ${ }^{16}$ 


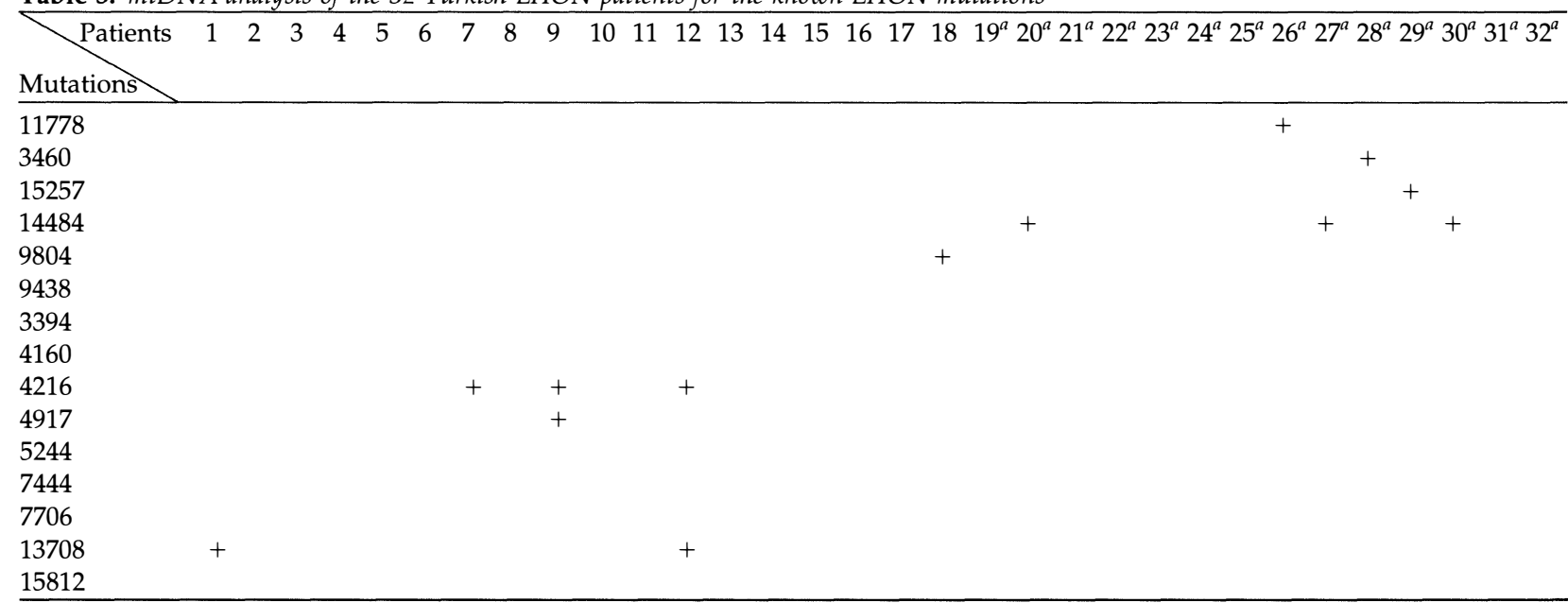

${ }^{a}$ The last 14 patients were analysed only for the primary LHON mutations at nucleotide positions 11778, 3460, 15257 and 14484.

The forward and reverse primers and restriction endonucleases for each LHON associated mutation are listed in Table 2.

All nucleotide positions are numbered according to the canonical Cambridge human mtDNA sequence. ${ }^{16}$

\section{Results}

The results of the LHON mutation analysis of the Turkish LHON patients are shown in Table 3.

The 11778, 3460, 14484 (three well-known primary LHON mutations) and 15257 mutation analysis in 32 patients

The primary LHON mutations were identified in 5 of 32 (16\%) patients. Three of them (patients 20, 27 and 30) carried the 14484 mutation, 1 carried the 3460 mutation (patient 28) and 1 carried the 11778 mutation (patient 26). None of the patients with the 14484 and 3460 mutations had a family history of visual loss. The patient with the 11778 mutation had a visually affected brother, maternal uncle and maternal aunt.

One patient harboured the 15257 LHON mutation (patient 29). This patient did not have a family history of LHON.

\section{The Complex IV-cytochrome c oxidase subunit III gene LHON mutation and secondary LHON mutation analysis in 18 patients}

One LHON proband harboured the 9804 primary LHON mutation. The 9804 mutation was verified in the patient's PCR-amplified mtDNA by using a forward amplification primer at nucleotide positions 9756-9775

(5' TCTCCCTTCACCATTTCCGA 3') and a reverse amplification primer at nucleotide positions $9848-9866$ (5' GATGAAGCAGATAGTGAGG 3') with the creation of a MaeIII (Boehringer, Mannheim, Germany) restriction site (GTNAC) caused by the mutation.
Molecular analysis of this mutation among the family members showed that the proband's asymptomatic close maternal relatives harboured the mutation and it was present in a heteroplasmic state in the family members including the proband.

Family analysis. Blood samples were obtained from the proband's sister (5 years older than the proband) and the proband's two children (a daughter and a son). None of these relatives has shown any signs of optic neuropathy. They were analysed in a similar fashion for the cytochrome $c$ oxidase/9804 mutation. We observed that the mutation was also carried in the proband's asymptomatic daughter, son and older sister.

None of the $18 \mathrm{LHON}$ probands harboured the Complex IV, COXIII/9438 LHON mutation.

Secondary mutations at np 4216, 4917 and 13708 were found in 4 of the $18 \mathrm{LHON}$ probands (22\%). One carried the 13708 mutation (patient 1), 1 carried the 4216 mutation (patient 7), 1 carried the 4216 and 4917 mutations (patient 9) and 1 carried the 4216 and 13708 mutations (patient 12). None of the patients with the secondary LHON mutations had a family history of visual loss.

\section{Discussion}

The frequency of three well-known primary LHON mutations in Turkish LHON patients is significantly lower than in the other populations reported to date. In the United Kingdom, 9\% of families tested had the 3460 mutation, $78 \%$ had the 11778 mutation and $13 \%$ had the 14484 mutation. ${ }^{17}$ In the study by Vilkki et al. ${ }^{18}$ in 19 Finnish families, $3(16 \%)$ had the 3460 mutation and 10 (53\%) had the 11778 mutation. The 11778 mutation accounts for $92 \%$ of families in the Japanese LHON population. ${ }^{19}$

In the Turkish LHON probands with the 11778, 3460 and 14484 mutations, 9\% harboured the 14484 mutation, $3 \%$ had the 11778 mutation and $3 \%$ had the 3460 mutation. The 14484 mutation appears to be the most 
frequent cause of LHON in our population, in contrast to the majority of previous reports in which 11778 is the most common mutation in the reported populations. ${ }^{17-20}$ On the other hand, this is comparable to a previous study where 14484 had been the most common mutation in LHON families of French Canadian origin. ${ }^{21}$

We found the fourth 9804 mutation associated LHON proband in the literature and the occurrence of the 9804 mutation in a heteroplasmic form in this patient is consistent with a significant pathogenetic role.

One of our patients carried the Complex III, cytochrome $b$ gene/15257 mutation. The patient with the 15257 mutation carried none of the 11778, 3460 and 14484 mutations. This finding is comparable with the results of those authors who indicate that the 15257 mutation has a primary pathogenetic importance in LHON, and contrary to the report of Oostra et al. ${ }^{12-15}$ On the other hand, our 15257 positive patient who lacks the 3460, 11778 and 14484 mutations may harbour an as yet unidentified primary mutation.

Our LHON probands are singletons except for 3 patients. One of the LHON patients with a positive family history carried the 11778 mutation, and the remaining 2 harboured none of 16 LHON mutations. In 10 of 29 patients who lack a family history of visual loss, the occurrence of LHON mutations most probably reflects the fact that the mutations have occurred recently and the presence of the mutation in the unaffected family members of the patient with the 9804 mutation may verify this hypothesis.

The molecular basis of the Turkish LHON population appears to be significantly different from that of other LHON populations studied to date in four distinctive features. First, the primary LHON-associated mtDNA mutations at nucleotide positions 11778,3460 and 14484 that account for the vast majority of LHON probands in previous reports was found only in the minority of the Turkish LHON probands. Second, the relative frequency of the 14484 mutation in our patients is higher than the other Complex I primary mutations, compatible with the study in French Canadian LHON patients. Third, in the absence of the common mutations, one LHON proband harboured the infrequent 9804 mutation. Fourth, the vast majority of our cases (91\%) did not have a family history of visual loss.

There are three hypotheses for the mitochondrial gene aetiology of LHON in the Turkish probands. The first possibility is that there may be additional point mutations in the mtDNA which are yet to be discovered that account for the visual loss in the Turkish LHON probands not associated with the known mutations. This is currently being investigated. Alternatively, the Turkish LHON probands not associated with the known mutations have the primary mutations that could have not shown up due to heteroplasmy. A population of mutant mtDNA confined to the optic nerves, retina and their vasculature may account for the LHON probands with negative blood tests. Finally, the disease may result from the interaction of multiple secondary LHON mutations, none of which produces the risk of LHON when present in isolation from the others. If the last possible mechanism is the one that is operating, it may account for the development of visual loss only in 2 Turkish probands, one carrying the 4216 and 4917 mutations, and the other with 4216 and 13708 mutations.

This study was supported by a grant in scope of the NATO Science Fellowship Programme from the Scientific and Technical Research Council of TURKEY (C.F.D.) and by a Clinical Investigator Development Award from the National Instiute of Neurological Disorders and Stroke and Basil O'Connor Starter Award No. 5-FY92-1033 from the March of Dimes Birth Defects Foundation, White Plains, NY (D.R.J.). We thank Xin Chan for his technical assistance.

\section{References}

1. Wallace DC, Singh G, Lott MT, et al. Mitochondrial DNA mutation associated with Leber's hereditary optic neuropathy. Science 1988;242:1427-30.

2. Huoponen K, Vilkki J, Aula P, Nikoskelainen EK, Savontaus M-L. A new mtDNA mutation associated with Leber hereditary optic neuroretinopathy. Am J Hum Genet 1991;48:1147-53.

3. Howell N, Bindoff LA, McCullough DA, et al. Leber hereditary optic neuropathy: identification of the same mitochondrial ND1 mutation in six pedigrees. Am J Hum Genet 1991;49:939-50.

4. Vilkki J, Savontaus M-L, Nikoskelainen EK. Segregation of mitochondrial genomes in a heteroplasmic lineage with Leber hereditary optic neuroretinopathy. Am J Hum Genet 1990;47:95-100.

5. Mackey D, Howell N. A variant of Leber hereditary optic neuropathy characterised by recovery of vision and by an unusual mitochondrial genetic etiology. Am J Hum Genet 1992;51:1218-28.

6. Johns DR, Neufeld MJ. Cytochrome $c$ oxidase mutations in Leber's hereditary optic neuropathy. Biochem Biophys Res Commun 1993;196:810-5.

7. Johns DR, Neufeld MJ. Cytochrome $b$ mutations in Leber hereditary optic neuropathy. Biochem Biophys Res Commun 1991;181:1358-64.

8. Brown MD, Voljavec AS, Lott MT, Torroni A, Yang C-C, Wallace DC. Mitochondrial DNA complex I and III mutations associated with Leber's hereditary optic neuropathy. Genetics 1992;130:163-73.

9. Johns DR, Berman J. Alternative, simultaneous complex I mitochondrial DNA mutations in Leber's hereditary optic neuropathy. Biochem Biophys Res Commun 1991;174:1324-30.

10. Brown MD, Yang C-C, Trounce I, Torroni A, Lott MT, Wallace DC. A mitochondrial DNA variant, identified in Leber hereditary optic neuropathy patients, which extends the amino acid sequence of cytochrome $c$ oxidase subunit I. Am J Hum Genet 1992;51:378-85.

11. Brown MD, Wallace DC. Spectrum of mitochondrial DNA mutations in Leber's hereditary optic neuropathy. Clin Neurosci 1994;2:138-45.

12. Johns DR, Smith KH, Savino PJ, Miller NR. Leber's hereditary optic neuropathy. Clinical manifestations of the 15257 mutation. Ophthalmology 1993;100:981-6.

13. Brown MD, Voljavec AS, Lott MT, McDonald I, Wallace DC. Leber's hereditary optic neuropathy: a model for mitochondrial neurodegenerative diseases. FASEB J 1992;6:2791-8. 
14. Oostra RJ, Bolhuis PA, Wijburg FA, Zorn-Ende G, BleekerWagemakers EM. Leber's hereditary optic neuropathy: correlations between mitochondrial genotype and visual outcome. J Med Genet 1994;31:280-6.

15. Oostra RJ, Bolhuis PA, Zorn-Ende I, de Kok-Nazaruk MM, Bleeker-Wagemakers EM. Leber's hereditary optic neuropathy: no significant evidence for primary or secondary pathogenicity of the 15257 mutation. Hum Genet 1994;94:265-70.

16. Anderson S, Bankier AT, Barrell BG, et al. Sequence and organisation of the human mitochondrial genome. Nature 1981;290:457-65.

17. Harding AE, Sweeney MG, Govan GG, Riordan-Eva P. Pedigree analysis in Leber hereditary optic neuropathy with a pathogenic mtDNA mutation. Am J Hum Genet 1995;56:72-6.
18. Vilkki J, Savontaus M-L, Nikoskelainen EK. Genetic heterogeneity in Leber hereditary optic neuropathy revealed by a mitochondrial DNA polymorphism. Am J Hum Genet 1989;45:206-11.

19. Nakamura M, Ara F, Yamada M, et al. High frequency of mitochondrial ND4 mutation in Japanese pedigrees with Leber hereditary optic neuropathy. Jpn J Ophthalmol 1992;36:56-61.

20. Nikoskelainen EK, Marttila RJ, Huoponen K, et al. Leber's 'plus': neurological abnormalities in patients with Leber's hereditary optic neuropathy. J Neurol Neurosurg Psychiatry 1995;59:160-4.

21. Macmillan C, Kirkham T, Fu K, et al. Pedigree analysis of French Canadian families with T14484C Leber's hereditary optic neuropathy. Neurology 1998;50:417-22. 